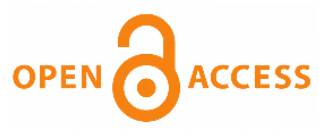

\title{
"More Practice-based Courses and Not Just a Load of Papers to Read": Youth Soccer Coaches Reflections on Coach Education Programs in Sweden
}

Authors' contribution:

A) conception and design of the study

B) acquisition of data

C) analysis and interpretation of data

D) manuscript preparation

\section{Krister Hertting}

Halmstad University, Sweden

ABSTRACT

In Sweden, the formal soccer coach education programs are divided into different levels and are also divided into youth coaching and senior coaching. This paper focuses on youth soccer coaches and their reflections on coach education programs. In the background section the Swedish context is described, as well as current research on coaches' education and learning. The aim of the paper was to investigate youth soccer coaches' reflections on coach education programs and to analyse their reflections by using a cultural approach to learning. The empirical material of the paper derives from a web-based questionnaire, posing questions about competence, learning and stress. The coaches were also invited to reflect on the question "how do you believe that soccer associations can educate good coaches?" There were 369 responses, and these were analysed using qualitative content analysis. Results indicated reflections about Flexibility in time, place and content, Mentorship supporting informal learning, Demanding mandatory education and emolument, Education focusing on wholeness and Education being based in practice. The conclusion was that decentralization of education and development of coaches' contexts, abilities and motivation to critically analyse aims and contents of coach education programs are improvement areas for learning and coaching practices. coaching, learning, coach education, youth sport, cultural learning theory

\section{Introduction}

Compared to countries such as the USA, Canada, and Great Britain, where sport is strongly connected to the school system, Sweden and the other Scandinavian countries have a culture of sport clubs based on voluntary leadership (Toftegard Stöckel, Strandbu, Solenes, Jörgensen \& Fransson, 2010). The coaches in general perform their mission and participate in coach education programs on their leisure time. In the European Commission's (2014) Eurobarometer on sport and physical activity, 25\% of Swedish respondents indicated that they gave their time to voluntary work in sport. This was the highest level in the European Union, which makes it relevant to set extra focus on the Swedish context. In 2014, almost 70\% of Swedish children aged 7-14 years reported belonging to a sports club, and Sweden had approximately 755,000 voluntary trainers, coaches, leaders and 
board members spread across 23,000 sports clubs (SSC, 2017). Soccer is the most common sport. Sport coaching in Sweden is based on voluntarism and there is a long tradition of voluntarism in Swedish civil society and children's and young people's sport is a central component of youth politics (Peterson, 2008). The European Commission (2007) highlighted sport as the most important social movement for health-enhancing physical activity, and identified it as an arena for promoting volunteerism and active citizenship. However, according to Peterson (2007) sport for children and youth are run by two central objectives: 'associaton nurturing', similar to the description by European Commission, and 'competition nurturing', described by Peterson (2007) as the sport logic itself focused on rules, goal achieving and results. In nurturing youth through sports this, according to Peterson (2007), leads to a conflictual relation between the missions. Echoing Habermas the conflictual relation could illustrate the struggle between democratic orientations and instrumental orders (Kennedy, 2015). Involvement in children's sports links closely to family life, and Wheeler (2011) and Green, Thurston, Vaage and Roberts (2015) highlighted how sports cultures are transmitted through families. A study by the Swedish Sports Confederation [SSC] (2004) showed that $80 \%$ of parents were involved in their own children's sports club.

The Swedish Football Association ${ }^{1}$ is divided into 21 regional football associations, which locally administer almost 3,200 clubs with a total of 650,000 players (SSC, 2017). The formal coach education program is divided into different levels, and this is further divided into youth coaching and senior coaching (Swedish Football Association, 2017). The system is harmonised with The European Football Association (UEFA) standards, and the youth soccer system consists of three levels of course packages (C, B and UEFA elite youth A). Each year approximately 10000 coaches participate in the coach education program.

\section{Coach education and learning}

A common view is that education is important for sustaining and developing quality of coaching (Mallett, Trudel, Lyle \& Rynne, 2009; Cushion, Nelson, Armour, Lyle, Jones, Sandford \& O’Callaghan, 2010; Bolter, Jones Petranek \& Dorsch, 2017). Studies point out that trained coaches can have more positive impacts on young athletes compared with non-trained coaches regarding psychosocial well-being and sport longevity (Hedstrom \& Gould, 2004; Sullivan, Paquette, Holt \& Bloom, 2012). However, studies also point out that there are limitations in coach education programs abilities to improve coaches (Werthner \&Trudel, 2006; Côté, 2006; Stoszkowski \& Collins, 2014). Werthner and Trudel (2006) highlighted the two learning metaphors acquisition (formal education) and participation (learning through experience), and elucidated that learning to coach is a complicated and idiosyncratic process which involves formal and informal settings as well as coaches reflections. Hence, it should be acknowledged that coaches learning occur in non-formal, informal and cooperative learning settings as well as in formal coach education programs (Côté, 2006; Piggot, 2012; Camiré, Trudel \& Forneris, 2014; Jones, Harris \& Miles, 2009).

Côté (2006) and Stoszkowski \& Collins (2014) argues on one hand that formal coach education risks focusing on knowledge transfer, missing dimensions of critical thinking, but on the other hand that formal coach education settings could be the only context where there is potential for coaches to develop critical thinking. In a study on female coaches' experiences of English coach education programs, Lewis, Roberts and Andrews (2015) found that there is often a gap between what is being provided in the programs and what the coaches find to be relevant knowledge. In some studies coaches express that formal education is of limited importance and courses often lack of relevant and practically useful knowledge (Nelson, Cushion \& Potrac, 2013; Camiré, Trudel \& Forneris, 2014). According to Stoder and Cushion (2014) coaches often base their reflections and actions on their existing life experience. It would though be rash to believe that coaches are uninterested in

\footnotetext{
${ }^{1}$ When the term 'association' is mentioned in the paper, it hereafter refers to the Swedish Football Association at a regional or national level.
} 
learning and developing their coaching skills. Being a coach is practical, and coaches ask for support including mentorship and other methods to adapt to their specific contexts (Nelson, Cushion \& Potrac, 2013; Camiré, Trudel \& Forneris, 2014; Griffiths \& Armour, 2012). This means that coaches ask for learning environments which supports their ongoing development as coaches, which is also acknowledged in a number of countries (Cassidy \& Kidman, 2010; Jones, Harris \& Miles, 2009). Cassidy and Kidman (2010) analysed official New Zealand documents about coach education policies and interviewed politicians involved in developing the documents. They came to the conclusion that there has been a paradigm shift and "... a move from an accredited and certified, standardized program, to an on-going professional development” (p. 320).

How can support structures for coach education and development be created? Cushion et al. (2010) highlighted that reflection, mentoring, and situated learning could structure learning processes and outcomes. Ryan and Sagas (2011) suggested supervision from managers to coaches and Gilbert and Trudel (2001) stated that socalled coaching pods could serve as a promoting structure for coaches in community-based sports associations. This means that "coaches of teams within similar athlete age groups could form a peer network and discuss coaching issues" (p. 32). Discussions above imply that coaches' learning is a social process (Lemyre, Trudel, Durand-Bush, 2007) that transcends formal educational structures and programs (Côté, 2006; Piggot, 2012). This could include mentorship, which is a contextualised and social process between an experienced person and a protégé, and can be considered as an investment in the whole person's growth (Jones, Harris \& Miles, 2009). Mentorship is a complex concept and can be formal or informal. Jones, Harris and Miles (2009) highlight three fundamental mentoring relationships; responsive (with a great degree of freedom for the protégé), interactive (characterized by open conversation and mutuality) and directive (where the mentor has a set agenda), based on for instance context, knowledge and relations.

\section{A cultural perspective on education and learning}

The above discussion implies cultural perspectives on learning and development, where learning is considered as ongoing sociocultural processes. According to Light (2011), research on sport education is generally informed by either social theory (such as Foucault, Bourdieu or Giddens) or learning theory (constructivism or social constructivism). Light (2011) connects situated learning and Bourdieu, and points out the central role of practice in learning, while Barker-Ruchti, Barker, Rynne and Lee (2016) means that the reflexive aspect is an important distinction between cultural and sociological perspectives on socialisation or enculturation. Hodkinson, Biesta and James (2007) develop a cultural approach to learning based on Dewey, Bourdieu and communities of practice. One main idea is that participation in learning cultures is practical, embodied, and social where participants are shaped by and are shaping cultures (Biesta, 2011). In other words: learning through 'becoming' and becoming through learning (Barker-Ruchti, Barker, Rynne \& Lee, 2016). However, people have different positions and dispositions and therefore also varying degrees of power to change cultures. Learning cultures are always based on value judgements of which type of knowledge that is desired in the current context (Biesta, 2011). People involved in education learn something for a reason and from someone, which means that educational cultures are framed by particular purposes (Biesta, 2011). This means that a cultural perspective begins with the normative question of what is aimed to achieve (often multiple aims) (Biesta, 2011). Biesta $(2009,2011)$ explains that education generally performs three interrelated functions: qualification, socialization and subjectification, which affect each other. Qualification refers to knowledge, skills, and understanding; socialization refers to becoming a member of particular social, cultural, and political orders; and subjectification refers to become independent in the current culture. This cultural approach aligns with Jones and Thomas' (2015) notions of scaffolding, where the authors as well as Barker-Ruchti, Barker, Rynne and Lee (2016) highlight that learning processes at micro levels also involves macro- and meso levels. 


\section{The rationale and aim of the paper}

The rationale of this paper is two-fold. Firstly, Quennerstedt, Öhman and Armour (2014) argue that explicit focus on learning theory often has played a limited role in research on physical education and sports. They state "Learning is at the heart of pedagogy, and PE teachers as well as sport coaches are essentially pedagogues" (p. 886). Linking theory and practice together emphasize the gap between research, policy and practical implications (Quennerstedt, Öhman \& Armour, 2014; Gilbert \& Trudel, 2004; Kirk \& Haerns, 2014; Jones, Morgan \& Harris, 2012). Secondly, Cushion, Nelson, Armour, Lyle, Jones, Sandford and O'Callagan (2010) point out that there is a gap in research about coaches teaching and learning preferences and needs. Therefore, the aim of the paper is to investigate youth soccer coaches' reflections on coach education programs and to analyse their reflections by using a cultural approach to learning.

\section{Method}

This paper analysed responses to an open-ended qualitative question posed as part of a larger study, which used an online questionnaire to investigate experiences of coaching, knowledge, and stress among Swedish voluntary youth soccer coaches. The questionnaire contained 68 multiple choice questions and two open-ended questions. It was based on previous research about coaches perceived competence, stress and education. Coaches were selected through systematic sampling. The starting point for sampling was a list of soccer clubs detailed at www.idrottonline.se where the majority of the Swedish sports clubs are registered. The Swedish Football Association is divided into 21 regional football associations. From each regional association, every $10^{\text {th }}$ club was selected. The first club on the list was randomly chosen and after that every $10^{\text {th }}$ club was selected. In each club, the head coach of every youth team (6-18 years of age) was invited to participate, which meant that more than one coach could represent one club.

Due to the underrepresentation of women in the sample, if there were two or more coaches for a team and one coach was female, then she was selected. In total, 1514 coaches received the questionnaire via email. The email contained a link to the database Education Survey Automation Suite (EvaSys) on-line system. In addition, information conforming to Swedish law concerning the ethical conduct of research (SFS, 2008) was provided emphasizing that participation in the research study was voluntary, and that participants were free to withdraw at any time without giving a reason why. The law also stresses confidentiality, which means that unauthorised persons have no access to the data. After two weeks, a follow-up reminder was sent, and 764 coaches (50.5\% of the sample, $78.5 \%$ men and $21.5 \%$ women) responded to the online questionnaire. 369 coaches answered the one question that formed the basis for this paper: namely (translated from Swedish), "how do you believe that soccer associations can educate good coaches?" The starting point of the analysis was qualitative content analysis (QCA) (Graneheim \& Lundman, 2004; Schreier, 2012) In general; focus in content analysis may be on manifest or latent content (Graneheim \& Lundman, 2004; Schreier, 2012). According to Schreier (2012), QCA is utilized when the content is less obvious and interpretation is needed, i.e., latent content. The starting point in this paper is a simple concept-driven coding frame that was constructed as described by Schreier (2012). When constructing the codes, the requirements of unidimensionality, mutual exclusiveness and exhaustiveness were considered. This concept contained two main codes: Form and Content. When these had been constructed, the material was analysed with focus on content. This led to 21 subcategories. The final step in analysis was to create main categories with the starting point in the subcategories. Five main categories were identified that were connected to the two main codes. The process of analysis was pending back and forth between parts and the whole. The final step of analysis was to bring context, theory and coach's reflections together in a synthesis. 


\section{Results}

The results will be presented with the starting point in the two main-codes Form and Content, and every main category will be described with quotations.

\section{Form}

When writing about the form of coach education three main categories appeared: Flexibility in time, place and content, Mentorship supporting informal learning, and Demanding mandatory education and emolument.

\section{Flexibility in time, place and content}

The coaches described flexibility as an important factor in coach education. This was expressed from different perspectives. One main concern was that weekend courses (which are common in a Swedish context) were time consuming and especially taking time from family life. Other forms were needed to be considered; "By arranging courses on other days/times. Everything doesn't need to be full day sessions at weekends." One solution to this was shorter, but more specialized, courses; "More courses focused on certain elements, to reduce the number of days, one-day courses in different specific subjects". This could for instance be on-going development through seminars on different topics, lectures, and meetings with other coaches.

Information technology was also mentioned to increase flexibility: "Interactive courses and tools. This means that you can study whenever you have the possibility", and "Online support would be good to develop, such as apps on your phone or iPad, but also from the computer at home. There is some, but this could be developed". It was also suggested that more courses should be organized in clubs, since this would increase flexibility; "I believe that the clubs must increase their short internal training and then perhaps we should have time to participate." Cooperation with other clubs was also highlighted. One coach sums up; "Education is good. Many do, however, have problems to find time, since they are coaches in addition to their regular job. It would be good if the clubs had internal training, perhaps in cooperation with clubs nearby. This would facilitate the time compared to travelling to courses". Flexibility was also mentioned in terms individualization of content, based on individuals: "That you have a course leader who has long experience of coaching and can meet individual coaches at their level of needs and knowledge, and also individualization based on functions"; "Courses for different leader functions, not only for coaches".

In summary, the prominent concern was about time-consuming weekend courses and ways to deal with this. The coaches suggested flexibility in terms of time, place and technical solutions. The coaches also stressed flexibility and individualization of content based on needs and functions in the club.

\section{Mentorship supporting informal learning}

The coaches mentioned different ways to support learning beyond formal education programs from a more able person or a mentor. One aspect was a control and support function, with overall responsibility: "Control and support from the club concerning goals, methods, results and feedback. This sets high demands on every club and requires a manager with overall responsibility and mandate to take actions." There was also a wish for coach educators to visit the clubs: "I wish that coach educators could come to the clubs and for instance observe a training session and then have a conversation about it to receive feedback". A common opinion was the idea of mentorship: "It would be useful to have some support from a more experienced coach-some kind of mentorship". Other coaches already had that experience: "Those who are interested in coach leadership should have a mentor to whom the coaches can turn to when they have concerns. I have tried to share my experiences as a coach for several years, and this has been positively met by less experienced coaches". The coaches also emphasized the importance of using civil competence: "There are several coaches on our team, and the best 
coach is an upper secondary teacher who knows how to meet youth. The parents appreciate his job". Other coaches emphasized their own competence; "I have more use of my bachelor degree in public health education than my coach education".

In summary, the coaches highlighted varying sources of learning beyond formal coach education programs. Mentorship was commonly mentioned, and thoughts about having a manager in the club and visiting coach educators from associations. Finally, the use of civil competence or learning trajectories was mentioned.

\section{Demanding mandatory education and emolument}

The coaches acknowledged the importance of formal coach education programs initiated by the soccer association, and several had thoughts about how to increase the coaches' participation. Coach education is recommended, but not mandatory, and the coaches highlighted this: "Before one is allowed to be responsible for a youth team, one should have had the insight in how Swedish soccer manages soccer for children and youth, i.e., a four-hour course." One coach wished to take it further; "Proper education (such as a license) should be required to be a coach." Other coaches were more focused on motivational factors: "See the individual and encourage those who have commitment but perhaps not the knowledge".

The coaches also mentioned financial incentive: "I believe that every club in Sweden should put much more effort into the coaches. Give them salary for their job and then make demands on participation in certain courses during their time as coaches. In that way we will have more competent coaches and players in the long run." Others suggested that the recruitment of young coaches/players need to be developed: "Parallel with their player education, teenage players should be taught basic coaching principles, and perhaps more young players can be involved in a children's team as assistant coaches", and "Early recruitment of youth who can't play themselves but are passionate for soccer. Engage them in small clubs and empower them".

In summary, the coaches stressed the importance of formal coaching education. This can be summarized in demands on mandatory courses, financial incitements, and recruitment/education of youth players.

\section{Content}

When coaches wrote about content of coach education, two main categories emerged: Education focusing on wholeness and Education being based in practice.

\section{Education focusing on wholeness}

There were critical comments stressing that too much emphasis was on technical soccer skills in coach education programs. This was considered being of secondary importance because many coaches had been playing soccer for many years: "The children and the team are the focus. Then game understanding followed by individual and technical skills". A holistic focus was requested. The coaches wrote about the meaning of policy: "Give distinct directions in courses concerning soccer association rules and guidelines. Follow up that everybody is coaching according to their club policy." The question about balance between competition and fun in youth soccer was raised: "Courses and above all a unified concept of how grassroots and elite soccer should be ran. The million dollar question is combining these".

Secondly, coaches emphasized that education should focus on player's development. There was a concern that the best players receive the most attention: "To point out at every course the importance that coach's role is to facilitate children's development, and to foster the best soccer players possible while focusing on every single individual". Another reflection was that education should focus more on social sciences (such as psychology, pedagogy and motivation climate): "Educate much more in teaching and learning processes: children and youth and their different learning processes". There was an emphasis on the holistic focus on soccer and youth: "It 
would be valuable if coaches are offered quality courses in team building, physical, and psychological development of youth including positive coaching and mental training".

In summary, coaches requested a more holistic oriented focus in coach education programs. Thoughts about education about policy programs, player development, social aspects and game understanding was highlighted, and there were critical voices meaning that too much emphasis was on technical skills in today's educational programs.

\section{Education being based in practice}

There were critical reflections meaning that coach education programs are too theoretical. Coaches wished for more practical elements: "More practice-based courses and not just a load of papers to read". There were experiences of programs when practical elements were present: "The best courses have a competent and experienced coach who has coached a group of players. It has had specific themes such as passing and receiving the ball. The coach also has presented aims and specific drills, things to consider and especially important details. Such a course offers much more profound knowledge than gazing at a PowerPoint with the heading Passing and receiving the ball". There were also suggestions about internship as a part of education programs: "Coaches can prepare and manage training sessions via internship in two different levels (grass root and elite) and with different age groups". The coaches also reflected on an exchange of experiences between coaches. One coach explained; "Above all, use competences in the club including coach meetings and discussions about leadership. What has worked/not worked experiences and so on".

There were also reflections on exchange between clubs: "I believe that a functioning network is really important. That coaches within and between clubs meet and discuss, have Facebook-groups, and so on." In addition, there were also thoughts about blue printing and learn from other sports: "We should cross boarders to other sports and learn from them. I feel that we sometimes acclaim ourselves too much. We already know everything". A common thought was that the soccer association should be closer to everyday coaching, and it was suggested that educators should visit the clubs: "The association should visit more often and initiate courses based on their observations". This could also involve practical elements: "More courses in the club supported by competent instructors from the association". Finally, there was critique that coach educators need to improve their skills: "The instructors at coaching courses must also develop. Soccer is not the same today as it used to be".

In summary, the coaches advocated decentralized and local programs based on experience and the direct needs of the clubs, i.e., a more practical focus. This was expressed as more practical focused education, internship, opportunities for exchange between coaches, local education in cooperation with football associations, and competent and updated coach educators: education being based in practice.

\section{Discussion}

The aim of this paper was to investigate youth soccer coaches' comments on coach education programs and coach development and analyzing this using a cultural approach to learning. The coaches emphasized flexibility, mentorship, demands, focus on holism and focus on practice.

The paper has limitations. From the total sample of 764 coaches only 369 participated in the open ended question about coach education, which decreases validity. The use of quotations enhanced the study's credibility (Westling Allodi, 2002), but since the instrument was a web-based and anonymous questionnaire it was not possible to identify quotations on an individual level. The coaches' responses might also have been affected by their varying abilities to express their thoughts in writing or by their different interpretations of the specific open question. Presumably, the coaches made a selection of thoughts that were plausible to reveal in this context from their perspective (Polit \& Beck, 2004). One should also consider that the question is based on soccer coaches' perspectives whereas other sports and activities involve voluntary coach responses and might involve 
other types of answers. All quotations were translated from Swedish, which risks losing some nuance. By doing interviews, the responses could have been more in depth, comparing to the broader image presented by 369 written reflections. The results should be viewed in the light of these limitations. In qualitative analysis it is plausible to consider transferability, which is "the range and limitations for application of the study findings, beyond the context in which the study was done" (Malterud, 2001, p.484), rather than generalization. In current study transferability to other similar contexts based on voluntary coaches should be relevant, since the study is based on theory, other similar international studies and a systematic sampling of participants.

Learning cultures are mutually shaping and being shaped by participants (Biesta, 2011) and Flexibility in time, place and content can be seen in the light of Sweden having a culture of voluntary leadership connected to clubs (Toftegaard Stöckel et al., 2010), and traditionally education has taken place on weekends. The coaches suggested flexibility in terms of time, place and technical solutions. The coaches also stressed flexibility and individualization of content based on needs and functions in the club. In a study by Wiersma and Sherman (2005), having a limited amount of time to volunteer, especially when having children of their own, was described as stressful by coaches. Comments on flexibility links to family life and stress alongside the mission as a coach (Wheeler, 2011; Green et al., 2015).

In accordance with Camiré, Trudel and Forneris, (2014), Nelson, Cushion \& Potrac, (2013), Griffiths and Armour, (2012) and Hertting and Kostenius, (2016), the categories Mentorship supporting informal learning and Education being based in practice support the idea of sources of learning beyond formal coach education programs. As Jones, Harris \& Miles (2009) points out, the coaches elucidate that mentorship could be in different constellations and contexts, for instance an experienced coach from the club or an official coach educator, which affects the relationship between mentor and protégé. This aligns with the notion of education as socialization, or learning through becoming (Biesta, 2009, 2011; Barker-Ruchti, Barker, Rynne \& Lee, 2016).

Coaches wished for Education focusing on wholeness (such as policy programs and social aspects) in contrast to what was perceived as too much emphasis on technical skills in educational programs, which expresses the conflictual relation between the double purposes of youth sport (Peterson, 2007). As Biesta (2011) elucidates, education often have multiple aims, based on sometimes conflicting value judgements. Nevertheless, coaches stressed the importance of formal coach education and there was a wish for mandatory courses and financial incitements for coaches, which again can be seen as an expression of the Swedish context, based on voluntarism (Toftegaard Stöckel et al., 2010), where paid coaches are rare within youth football and education is recommended but not mandatory. The qualification aspect was considered as important, but aims and content was contested by the coaches.

To summarize, a decentralized, flexible, practice-based and mandatory education, where mentors can play a role was proposed by the coaches. The coaches focused primarily on coach development either in informal, non-formal or formal settings. Echoing Biesta (2011), soccer is a practical, embodied, and social activity: a cultural expression which is shaping people and is also being shaped by people, based on power positions and dispositions. There is a comprehensive formal coach education system within Swedish soccer, but coach development is largely informal and also non-formal (Camiré, Trudel \& Forneris, 2014; Lemyre, Trudel \& Durand-Bush, 2007; Cushion et. al., 2010; Cotë, 2006). As mentioned, coach education is strongly recommended in youth soccer in Sweden but not mandatory when coaching children and coach training often take place in the clubs. The specific club context serves as a central socialization arena for coaches, and a local club culture emerges including former experiences as a player, local club guidelines, common club events, and informal coach meetings in or between teams in the club. Therefore, it makes sense that coaches want qualification to be part of the informal settings surrounding the club. Coaches requested a contextualized learning environment which could be met by for instance Gilbert's and Trudel's (2001) notion of coaching pods or other types of contextualised mentoring programs (Jones, Harris \& Miles, 2009). 
Corresponding to Biesta $(2009,2011)$ the educational aims for youth sport is basically manifold, including what Peterson (2007) refers to as association and competition nurturing. Coaches were questioning current orders of education programs as being too technical, which correspond to the need for critical thinking within coach education (Lewis, Roberts \& Andrews, 2015; Stoszkowski \& Collins, 2014). The qualification aspect becomes relevant to discuss and problematize in policy and education of youth soccer coaches. This could help to bridge the gap between offers in coach education and relevant knowledge for coaches (Lewis, Roberts \& Andrews, 2015).

\section{Conclusion}

In conclusion, decentralization of education and development of coaches' contexts, abilities and motivation and to critically analyse aims and contents of coach education programs are areas for improvement in coach education and learning in youth soccer.

\section{REFERENCES}

Barker-Ruchti, N., Barker, D., Rynne, S.B. \& Lee, J. (2016). Learning cultures and cultural learning in high-performance sport: opportunities for sport pedagogues. Physical Education and Sport Pedagogy, 21 (1), 1-9.

Biesta, G. (2009). Good education in an age of measurement: On the need to reconnect with the question of purpose in education, Educational Assessment, Evaluation and Accountability, 21 (33), 33-46.

Biesta, G. (2011). From learning cultures to educational cultures: Values and judgements in educational research and educational improvement, International Journal of Early Childhood, 43, 199-210.

Bolter, N.D., Jones Petranek, N. \& Dorsch, T.E. (2017) Coach, parent, and administrator perspectives on required coaching education in organized youth sport. International Journal of Sports Science \& Coaching, 0 (0), 1-11. https://doi.org/10.1177/1747954117735718

Camiré, M., Trudel, P. \& Forneris, T. (2014). Examining how model youth sport coaches learn to facilitate positive youth development. Physical Education and Sport Pedagogy, 19 (1), 1-17.

Cassidy, T. \& Kidman, L. (2010). Initiating a national coaching curriculum: A paradigmatic shift? Physical Education and Sport Pedagogy, 15 (3), 307-322.

Côté, J. (2006). The development of coaching knowledge. International Journal of Sports Science \& Coaching, 1 (3), $217-$ 222.

Cushion, C., Nelson, L., Armour, K., Lyle, J., Jones, R., Sandford, R. \& O’Callaghan, C. (2010). Coach Learning \& Development: A Review of Literature. London: Sports Coach UK.

European Commission. (2007). White paper on sport. Brussels: Publications Office.

European Commission. (2014). Special Eurobarometer. Sport and physical activity. Brussels: TNS Opinion \& Social.

Gilbert, W.D. \& Trudel, P. (2001). Learning to coach through experience: Reflection in model youth sport coaches. Journal of Teaching in Physical Education 21: 16-34.

Gilbert, W.D. \& Trudel, P. (2004). Analysis of Coaching Science Research Published From 1970-2001. Research Quarterly for Exercise and Sport, 75 (4), 388-399.

Graneheim, U.H. \& Lundman, B. (2004). Qualitative content analysis in nursing research: Concepts, procedures and measures to achieve trustworthiness. Nurse Education Today, 24, 105-112.

Green, K., Thurston, M., Vaage, O. \& Roberts, K. (2015). '[We're on the right track, baby], we were born this way'! Exploring sports participation in Norway. Sport, Education and Society, 20 (3): 285-303.

Griffiths, M. \& Armour, K. (2012). Mentoring as a formalized learning strategy with community sports volunteers. Mentoring \& Tutoring: Partnership in Learning 20(1): 151-173.

Hedstrom, R. \& Gould, D. (2004). Research in Youth Sports: Critical Issues Status. White Paper Summaries of the Existing Literature. Michigan State University: Institute for the study of youth sports.

Hodkinson, P., Biesta, G. \& James, D. (2007). Understanding learning cultures. Educational Review, 59 (4), 415-427.

Jones, R.L. \& Thomas, G.L. (2015). Coaching as 'scaffolded' practice: Further insights into sport pedagogy, Sports Coaching Review, 4 (2), 65-79, DOI: 10.1080/21640629.2016.1157321 
Jones, R.L., Harris, R., \& Miles, A. (2009). Mentoring in sport coaching: a review of the literature. Physical Education and Sport Pedagogy, 14 (3), 267-284.

Jones, R.L., Morgan, K. \& Harris, K. (2012). Developing coaching pedagogy: seeking a better integration of theory and practice. Sport, Education and Society, 17 (3), 313-329.

Kennedy, P. (2015). Using Habermas to crack the European football championships. Sport in Society, DOI: $10.1080 / 17430437.2015 .1088722$

Lemyre, F., Trudel, P., \& Durand-Bush, N. (2007). How Youth-Sport Coaches Learn to Coach, The Sport Psychologist, 21, 191-209.

Lewis, C.J., Roberts, S.J., \& Andrews, H. (2015). 'Why am I putting myself through this?' Women football coaches' experiences of the Football Association's coach education process, Sport, Education and Society, Doi:10.1080/13573322.2015.1118030

Light, R.L. (2011). Opening up learning theory to social theory in research on sport and physical education through a focus on practice, Physical Education and Sport Pedagogy, 16 (4), 369-382.

Malterud, K. (2001). Qualitative research: standards, challenges, and guidelines. The Lancet, 358, 483-488.

Nelson, L., Cushion, C. \& Potrac, P. (2013). Enhancing the provision of coach education: The recommendations of UK coaching practitioners. Physical Education and Sport Pedagogy, 18 (2), 204-218.

Peterson, T. (2007). Landskrona BoIS as an Environment for Nurturing and Education. Soccer \& Society, 8 (1), $125-139$.

Peterson, T. (2008). Föreningsfostran och tävlingsfostran. En utvärdering av statens stöd till idrotten. SOU $2008: 59$. [Association nurturing and competition nurturing. An assessment of the state support for sports] Stockholm: Swedish Government.

Piggot, D. (2012). Coaches' experiences of formal coach education: A critical sociologicalinvestigation. Sport, Education and Society, 17 (4), 535-554.

Polit, D.F. \& Beck, C.T. (2004). Nursing Research. Principles and Methods. Philadelphia: Lippincott Williams \& Wilkins.

Quennerstedt, M., Öhman, M., \& Armour, K. (2014). Sport and exercise pedagogy and questions about learning. Sport, Education and Society, 19 (7), 885-898.

Ryan, T.D. \& Sagas, M. (2011). Coaching and family: The beneficial effects of multiple role membership. Team Performance Management 17(3/4): 168-186.

Schreier, M. (2012). Qualitative Content Analysis in Practice. London: SAGE.

Stoder, A. \& Cushion, C.J. (2014). Coaches' learning and education: A case study of cultures in conflict, Sports Coaching Review, 3 (1), 63-79.

Stoszkowski, J. \& Collins, D. (2014). Communities of practice, social learning and networks: Exploiting the social side of coach development. Sport, Education and Society, 19 (6), 773-788.

Sullivan, P., Paquette, K.J., Holt, N.L., \& Bloom, G.A. (2012). The relation of coaching context and coach education to coaching efficacy and perceived leadership behaviors in youth sport. The Sport Psychologist, 26, 122-134.

Swedish Football Association (2017). Coach education in Swedish football. [on-line]. Retrieved from http://fogis.se/tranare/svffs-tranarutbildning/ (accessed on October 10, 2017).

Swedish Sports Confederation (2004). Föräldraengagemang i barns idrottsföreningar [Parents commitment in children's sports clubs]. FoU Report 2004:8. Stockholm: Swedish Sports Confederation.

Swedish Sports Confederation (2017). Idrotten i siffror. [Sports in numbers]. [on-line] Retrieved from http://www.rf.se/ (accessed October 28, 2017).

Toftegard Stöckel, J., Strandbu, Å., Solenes, O., Jörgensen, P. \& Fransson, K. (2010). Sport for children and youth in the Scandinavian countries. Sport in Society 13(4): 625-642.

Vaismoradi, M., Turunen, H., \& Bondas, T. (2013). Content analysis and thematic analysis: Implications for conducting a qualitative descriptive study. Nursing and Health Sciences, 15, 398-405.

Werthner, P., \& Trudel, P. (2006). A New Theoretical Perspective for Understanding How Coaches Learn to Coach. The Sport Psychologist, 20: 198-212.

Westling Allodi, M. (2002). Children's experiences of school: Narratives of Swedish children with and without learning difficulties. Scandinavian Journal of Educational Research, 46: 181-205.

Wheeler, S. (2011). The significance of family culture for sports participation. International Review for the Sociology of Sport, 47 (2): 235-252.

Wiersma L D and Sherman C P (2005) Volunteer Youth Sport Coaches' Perspectives of Coaching Education/Certification 
and Parental Codes of Conduct. Research Quarterly for Exercise and Sport 76(3): 324-338.

\section{AUTHOR'S ADDRESS:}

\section{Krister Hertting}

Center of Research on Welfare, Health and Sport

Halmstad University

Box 823

30118 Halmstad, Sweden

E-mail: Krister.Hertting@hh.se

Received: 3 January 2019; Accepted: 14 June 2019 